\title{
Increasing Efficiency at the NTF by Optimizing Model AoA Positioning
}

\author{
Bradley L. Crawford ${ }^{1}$ \\ NASA Langley Research Center, 4 Langley Blvd, Hampton, Virginia 2368-2199 \\ Courtney Spells ${ }^{2}$ \\ Jacobs Sverdrup, 3 Langley Blvd, Hampton, Virginia 2368-2199
}

The National Transonic Facility (NTF) at NASA Langley Research Center (LaRC) is a national resource for aeronautical research and development. The government, military and private industries rely on the capability of this facility for realistic flight data. Reducing the operation costs and keeping the NTF affordable is essential for aeronautics research. The cost concern here is the liquid nitrogen $\left(\mathrm{LN}_{2}\right)$ and how much is used in the process of setting the model pitch. Tests were conducted at the NTF in January 2005 to reduce lag in the angle of attack (AoA) data used by the model pitch control system. Lag in both the filter and the digital voltmeter (DVM) contribute to long set times between data points. Reducing these lags was investigated and is discussed here.

\section{Introduction}

The current $\mathrm{LN}_{2}$ cost is around $\$ 90$ per ton and NTF can use a ton in about 4 seconds when operating at high Reynolds number conditions. In NTF's effort to reduce cost, a test was undertaken to determine how to reduce the average range of time between data points which is currently $15 \mathrm{~s}-18 \mathrm{~s}$. A substantial amount of money can be saved by reducing this time. For example, in a recent test the customer required 5000 data points. If a 4 second per data point reduction could be achieved then that would equate to a savings of roughly $\$ 450,000$.

Putnam $^{1}$ and Kegelman ${ }^{2}$ take a global look at the productivity improvement needs at the NTF in the mid to late 1990s but this test focused on reducing costly nitrogen consumption through reducing lag in the control system. Specifically it concentrated on two aspects of the AoA signal being provided to the control system. The first area is filtering the signal dynamics and the second deals with removing the integrating DVM from the system. Both of these systems create lag that could be reduced but need to be studied to ensure there is not an unacceptable loss in data quality.

NTF typically uses an active 4 pole Bessel low-pass filter with the cut-off frequency set to $0.4 \mathrm{~Hz}$. This smoothes the dynamic accelerometer signal to an acceptable level but it induces a lag of about $0.7 \mathrm{~s}$ (at a 2 $\mathrm{deg} / \mathrm{s}$ slew rate). As the cut-off frequency is increased the lag will decrease but the dynamics will have more influence on the AoA reading. Doing this has the potential of reducing $0.5 \mathrm{~s}$ of lag out of the system as long as the data quality remains within acceptable levels.

The integrating DVM, by its nature, introduces lag into the system. Integrating at 10 power line cycles coupled with the overhead associated with processing the readings creates about $0.25 \mathrm{~s}$ to $0.33 \mathrm{~s}$ of lag. Removing them from the system would have many advantages, it would: eliminate this lag, not require

\footnotetext{
1 Aerospace Technologist, Aeronautics Systems Engineering Branch, MS 238, Senior Member.

${ }^{2}$ Wind Tunnel Test Engineer, Center Operations Directorate, MS 267
} 
calibration any more, and take old and failing pieces of equipment out of the system. The method being attempted here is a two-channel analog method. Where one channel would be set to high resolution for accurate readings between $\pm 7 \mathrm{deg}$. and the other one would be set to a higher range with less resolution for taking less critical measurements at higher angles.

Some gains can be made through "tweaking" the filter and removing the DVM but most significantly this test revealed some shortcomings in the way NTF has chosen to process the AoA signal and send it to the control system.

\section{NTF Model Attitude Control System}

The current NTF model pitch control system configuration (Figure I) has the determining sensor far removed from the angle setting apparatus. This configuration is driven by the perceived need to have the model pitch angle set to within a tight tolerance (typically $0.03-0.05$ ) of the target alpha angle (alpha is the model pitch angle with corrections such as flow angularity and roll included). The tighter this tolerance, the more time and resources are required to achieve the desired angle set point. In the case of NTF, the AoA sensor is an onboard (the model) accelerometer that corrects for sting whip induced bias ${ }^{3}$. Being that the accelerometer is in a dynamic environment, filtering is required to achieve a static representation of the signal. Following filter conditioning, the analog signal can be fed either directly into the analog input of the NEFF Data Acquisition Unit (DAU), or can be digitized and fed into the DAU digital input. In order to achieve 1 drag count accuracy $\left(C_{d}=0.0001\right)$, a $0.01^{\circ 4}$ angle measurement accuracy is required; to achieve this accuracy using analog input, the NEFF DAU must be put into auto-range mode. Auto-range mode at the NTF data system is not fast enough to accommodate all of the typical 128 input channels; much less the additional pressures being measured from the model or the tunnel. Therefore a highly accurate integrating DVM is used to digitize the signal and output it to a data system digital channel.

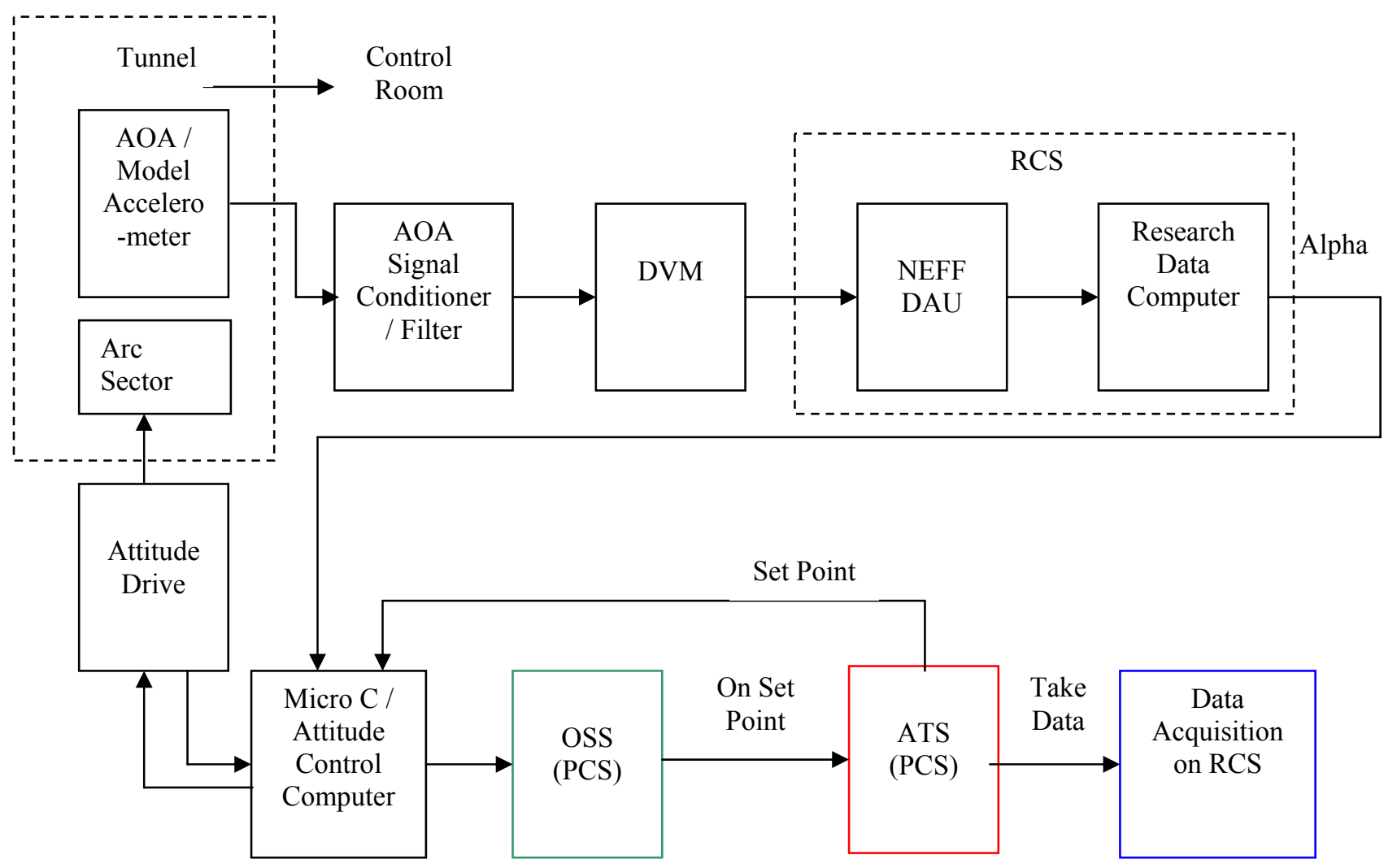

Figure 1: Model attitude control signal path 
The NEFF DAU is actually a sub-system of the Research Computer System (RCS). Employing the Research Data Computer, RCS is responsible for continuously collecting channel inputs from a number of tunnel systems, including pressure data from the tunnel and the model, balance data, strain gauge data, internal flow rake data, temperature data and model attitude data. Computations and alarm checks are performed, and this information is displayed on the workstations around the tunnel control room. From the workstations, test personnel are able to monitor near-real-time model attitude measurements.

The current computed model position is sent from RCS to Micro C, which is the attitude control computer. Micro $\mathrm{C}$ also receives the current requested model attitude set point from Automatic Test Sequencing (ATS) which is a program on the Process Control System (PCS). Micro C compares the measured angle to the requested angle, and makes an estimate on how much to move the model to attain the desired angle set point without overshooting. If the angle is overshot, the model angle will be over-corrected before again attempting to get on set point. This is done so the model angles are always attained from the same direction (usually approached from below) in order to avoid any hysteresis effects on the data.

The angle estimate is sent to the attitude drive. The attitude drive moves the arc sector in the test section to change the angle of attack of the model. The speed at which Micro $\mathrm{C}$ receives positioning data from RCS and the attitude drive's response determines how fast the model is able to get on set point. There is direct feedback between Micro $\mathrm{C}$ and the attitude drive. Micro $\mathrm{C}$ sends pitch control information to the attitude drive as the attitude drive sends pitch feedback to Micro C.

Micro C sends the current set point, feedback (the current position of the model), in limits tolerances and the stability time limit to the On Set Point Status (OSS) program on PCS. Tolerances and the stability time are decided before a test begins. OSS calculates the absolute value of the feedback minus the set point and checks that the calculated value is less than or equal to the in-tolerance limits. Once OSS reads the model attitude is in-limits, an in-limits timer is started. This timer is usually set between 2 and 4 seconds, depending on the model. An "on set point" signal is sent out once the in-limits time has reached the given stability time.

ATS receives the "on set point" signal from OSS. ATS checks that all parameters (Mach number, tunnel temperature, and tunnel pressure and model attitude) are on set point. Once all set points have been met, a "take data" signal is sent to the RCS.

RCS receives the "take data" signal and waits a specified amount of time for settling, which allows ESP surface pressures on the model to equalize for accurate readings. Readings are collected for a specified number of seconds (normally at $10 \mathrm{~Hz}$ for 2 seconds), and RCS computes an average from the 20 readings. The data is then written to an archive file and to a raw data file. Once the data is recorded, a new angle set point is requested through ATS and the process begins again.

There are many ways to set the model attitude in a wind tunnel and there can be variations between tests. Table 1 below shows how a few different facilities "typically" accomplish it. Some of the factors involved in the amount of time required to set the position are: whether the sensor is on-board the model and requires filtering or not, response time of the attitude detection sensor and tolerance around the set point are a few. 


\begin{tabular}{|c|c|c|c|c|c|c|c|c|}
\hline $\begin{array}{l}\text { Info. } \\
\text { acquired } \\
\text { from }\end{array}$ & Facility & $\begin{array}{l}\text { Speed } \\
\text { Regime }\end{array}$ & $\begin{array}{l}\text { Pitch } \\
\text { setting } \\
\text { sensor }\end{array}$ & $\begin{array}{l}\text { Setting } \\
\text { tolerance } \\
\text { (deg) }\end{array}$ & $\begin{array}{l}\text { Pitch } \\
\text { reading } \\
\text { sensor }\end{array}$ & $\begin{array}{l}\text { Pitch } \\
\text { reading } \\
\text { accuracy } \\
\text { (deg) }\end{array}$ & $\begin{array}{l}\text { Feedback } \\
\text { system }\end{array}$ & $\begin{array}{l}\text { Typical } \\
\text { set point } \\
\text { Time } \\
\text { (pitch } \\
\text { pause) }\end{array}$ \\
\hline $\begin{array}{l}\text { Joel } \\
\text { Hoffman } \\
\text { NASA } \\
\text { Ames }\end{array}$ & $9 \times 7$ & $\begin{array}{l}\text { Super } \\
\text { sonic }\end{array}$ & $\begin{array}{l}2 \text { sets of } \\
\text { dual } \\
\text { speed } \\
\text { resolvers }\end{array}$ & +-0.05 & $\begin{array}{l}\text { Inertial } \\
\text { accel. }\end{array}$ & $\begin{array}{l}\text { Better } \\
\text { than } \\
0.01\end{array}$ & $\begin{array}{l}\text { Automated } \\
\text { closed loop }\end{array}$ & $6.5 \mathrm{~s}$ \\
\hline $\begin{array}{l}\text { Joel } \\
\text { Hoffman } \\
\text { NASA } \\
\text { Ames }\end{array}$ & $11^{\prime}$ & $\begin{array}{l}\text { Tran } \\
\text { sonic }\end{array}$ & $\begin{array}{l}2 \text { sets of } \\
\text { dual } \\
\text { speed } \\
\text { resolvers }\end{array}$ & +-0.05 & $\begin{array}{l}\text { Inertial } \\
\text { accel. }\end{array}$ & $\begin{array}{l}\text { Better } \\
\text { than } \\
0.01\end{array}$ & $\begin{array}{l}\text { Automated } \\
\text { closed loop }\end{array}$ & $6.5 \mathrm{~s}$ \\
\hline $\begin{array}{l}\text { David } \\
\text { Rollins/ } \\
\text { Mark } \\
\text { Skelley } \\
\text { AEDC }\end{array}$ & $\begin{array}{l}\text { PWT } \\
16 T\end{array}$ & $\begin{array}{l}\text { Tran } \\
\text { sonic }\end{array}$ & $\begin{array}{l}\text { 64-turn } \\
\text { absolute } \\
\text { resolver }\end{array}$ & +-0.02 & $\begin{array}{l}\text { 64-turn } \\
\text { absolute } \\
\text { resolver }\end{array}$ & $\begin{array}{l}\text { Better } \\
\text { than } \\
0.01\end{array}$ & $\begin{array}{l}\text { Automated } \\
\text { closed loop }\end{array}$ & $5 s$ \\
\hline $\begin{array}{l}\text { Dan } \\
\text { Cole } \\
\text { NASA } \\
\text { Langley }\end{array}$ & $\begin{array}{l}\text { Unitary } \\
\text { Plan } \\
\text { Wind } \\
\text { Tunnel }\end{array}$ & $\begin{array}{l}\text { Super } \\
\text { sonic }\end{array}$ & $\begin{array}{l}\text { Inertial } \\
\text { accel. }\end{array}$ & +-0.1 & $\begin{array}{l}\text { Inertial } \\
\text { accel. }\end{array}$ & $\begin{array}{l}\text { Better } \\
\text { than } 0.2\end{array}$ & $\begin{array}{l}\text { Automated } \\
\text { closed loop }\end{array}$ & $\begin{array}{l}10 s- \\
15 s\end{array}$ \\
\hline $\begin{array}{l}\text { Joseph } \\
\text { Panek } \\
\text { NASA } \\
\text { Glenn }\end{array}$ & $8 \times 6$ & $\begin{array}{l}\text { Tran } \\
\text { sonic }\end{array}$ & pot & +-0.1 & $\begin{array}{l}\text { Inertial } \\
\text { accel. }\end{array}$ & $\begin{array}{l}\text { Better } \\
\text { than } \\
0.02\end{array}$ & $\begin{array}{l}\text { Automated } \\
\text { closed loop }\end{array}$ & $\begin{array}{l}10 s- \\
15 s\end{array}$ \\
\hline
\end{tabular}

Table 1: Characteristics of different facility model attitude controls

\section{Timing}

Although the process as described above may vary from test to test and set-up, it remains excruciatingly slow. The most significant time-consuming factors within a test are the conditions which contribute to model dynamics such as Mach number, dynamic pressure (q) and the AoA angle. Dynamics contribute to the time between points mostly by affecting the in-limits timer. If any readings go out of limits during this time, the timer resets. There are many occasions in periods of high dynamics that a manual override has to be initiated to take the data so the test can proceed.

NTF has long recognized that the time between data points was significant, averaging somewhere between $15 \mathrm{~s}$ and $18 \mathrm{~s}$. During the main portion of test 153 , the averaged time between points was found to be $16.2 \mathrm{~s}$. (Data points above 30s were removed from this average - although these points represented occurrences that were a part of regular testing, they do not reflect the times being addresses by this particular timereduction study. These removed occurrences represent many things such as shift change, lunch break, model change, tunnel condition change, etc.) There are 2 plots in Figure 2 that show the time distribution for this test. One is a histogram and the other shows the times in chronological order. The chronological order chart has a distinct stratification pattern of either $0.36 \mathrm{~s}$ or $0.72 \mathrm{~s}$. This is an artifact of the resolution at which the time data was taken. 

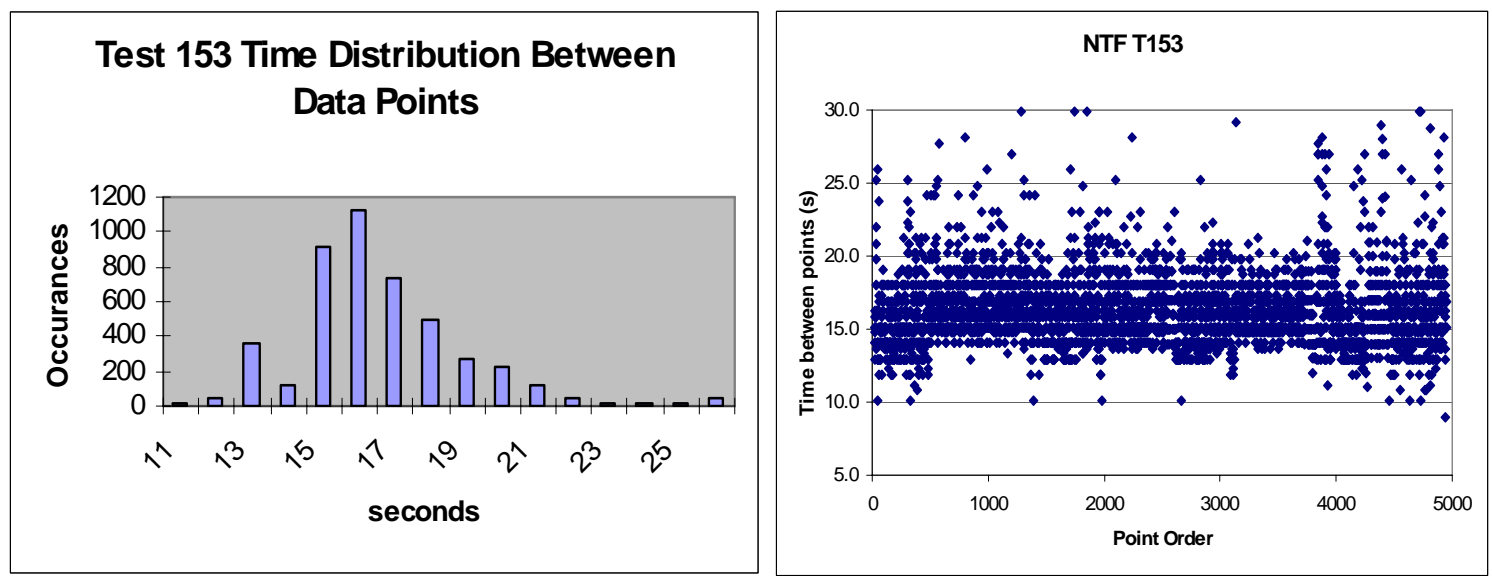

Figure 2: Timing distribution, Histogram (left) and in chronological order (right)

Representative samples of the timing from one point to the next are plotted in Figures 3 and 4 . They show the intermediate events and their corresponding times and how they contribute to the overall time. A less rigorous method of establishing the set point could save a large quantity of time and money.

\section{Point Timing}

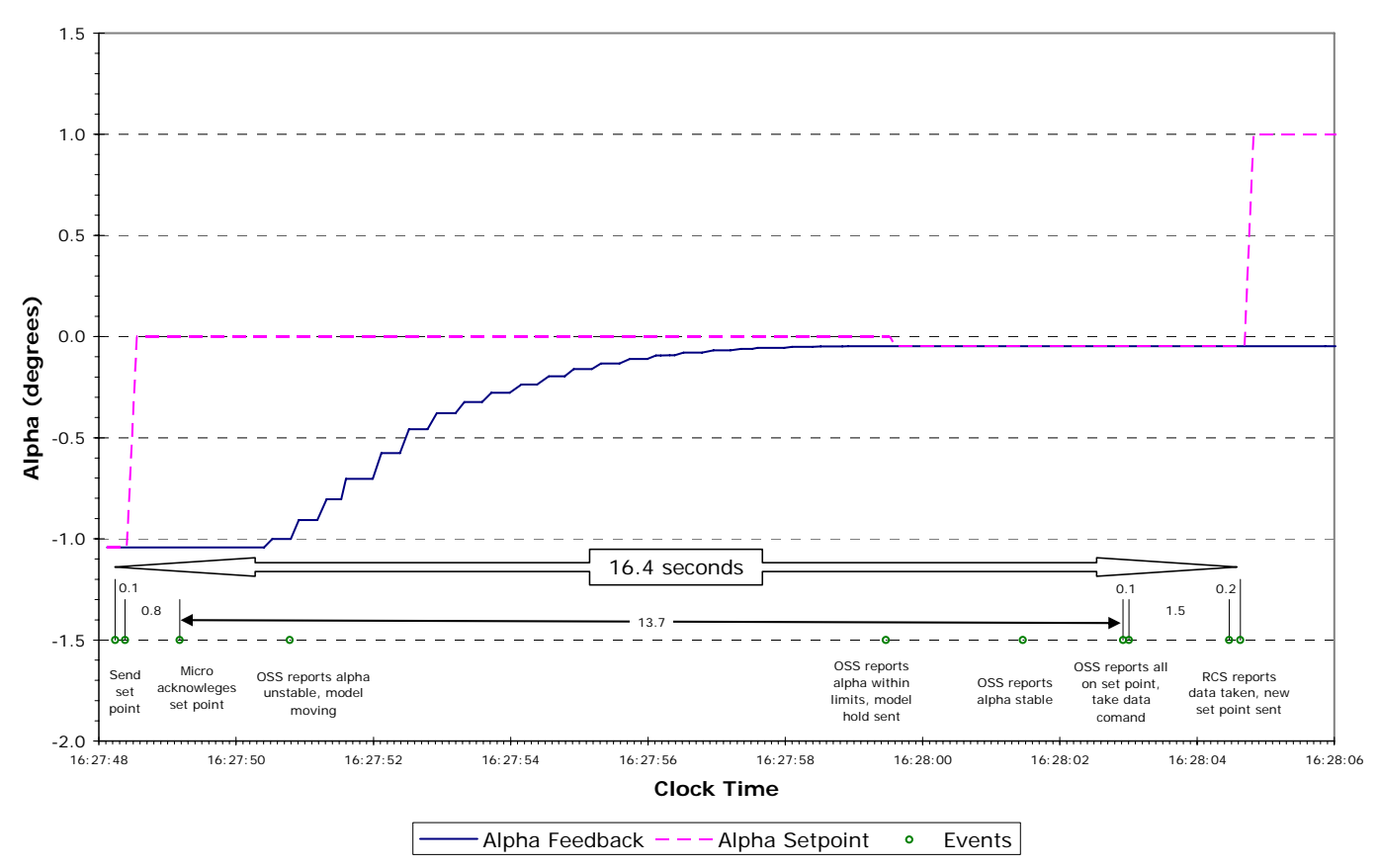

Figure 3: Intermediate timing between data points from NTF test 153 
Point Timing

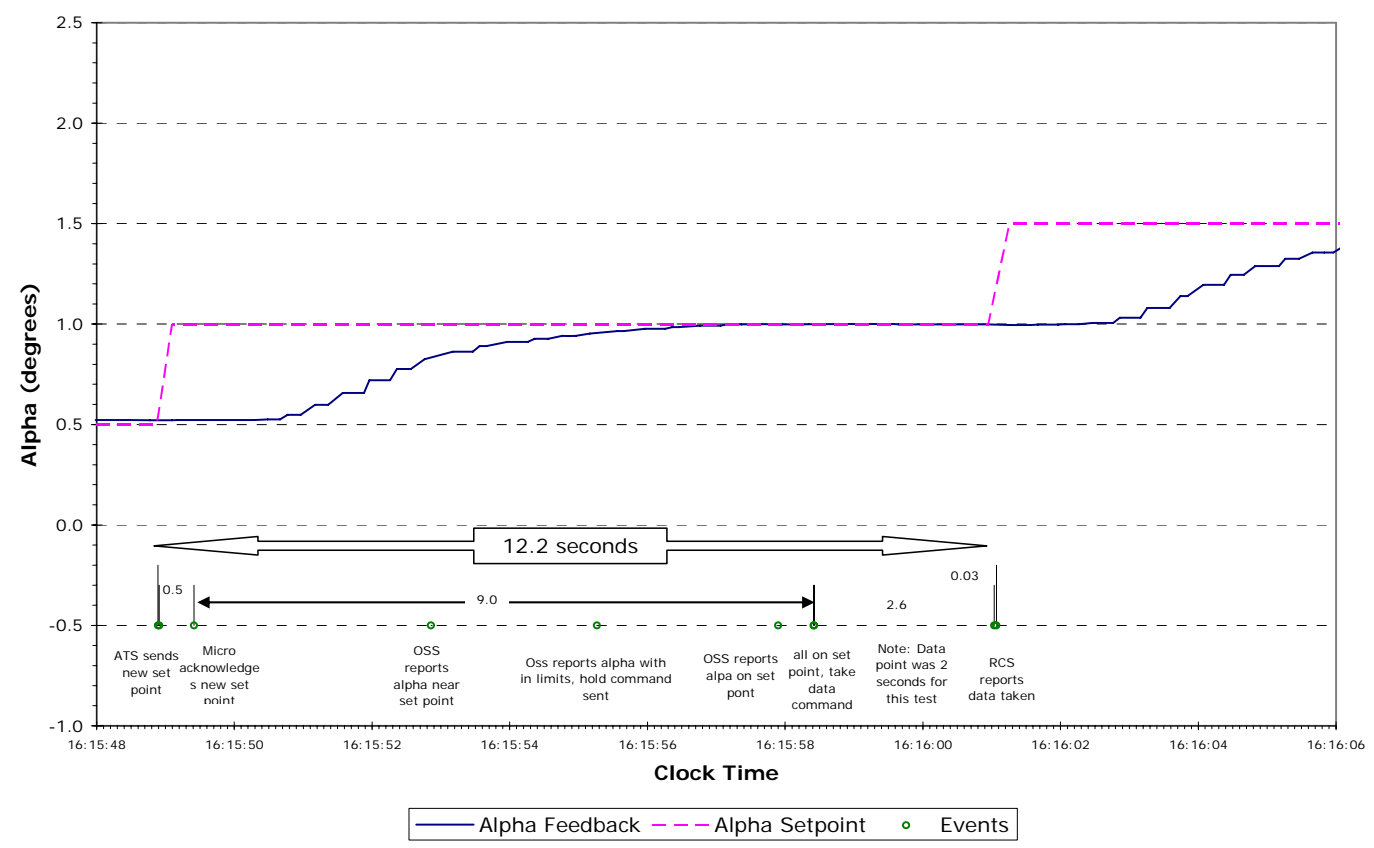

Figure 4: Intermediate timing between data points from NTF test 164

\section{Test Procedure}

This test was conducted as an "add-on" or "piggy back" to test T153 at NTF. This is a typical way for wind tunnels to conduct instrumentation testing in their facilities. Investigators either install the new method and record data from the instrument (but don't apply the readings to the research data) or they set aside time at the end of the customer's test to evaluate the new method. In this evaluation test, time was set aside at the end of the customer test.

NTF typically uses a 4 pole low pass active filter with a $0.4 \mathrm{~Hz}$ cut-off frequency to smooth the AoA signal from the onboard accelerometer. The objective here was to increase the cut-off frequency in the filter and assess the data quality as compared the data taken at the different cut-off frequencies. The cut-off frequencies chosen were, $0.4 \mathrm{~Hz}, 1.2 \mathrm{~Hz}$ and $4 \mathrm{~Hz}$. A switching device was built to enable the quick change between cut-off frequencies and inserted in the filter card. Following the test plan the cut-off frequencies were switched and polars were run at Mach numbers of 0.0, 6.4, 7.0 and 7.4 with q varying from 0 (at $\mathrm{M}=0$ ) and 710 to 2700 while the tunnel was operational. The polars were run in a pitch pause fashion with most polars having an AoA setting from $-3^{\circ}$ to $4^{\circ}$ with $0.5^{\circ}$ degree increments. A few polars were run from $8^{\circ}$ to $15^{\circ}$ with $0.5^{\circ}$ degree increments to test the two-channel analog method discussed below.

Since the DVM is an integrating device, it contributes to the lag in the AoA signal path. Another objective of this test was to determine if the DVM could be eliminated. To do this, a reasonable alternative method had to be found - the method proposed was a two-analog channel method as outlined in Appendix I. This two-analog channel method, however, would require a "philosophical" change: instead of requiring AoA measurement accuracy to within $0.01^{\circ}$ at all pitch angles, this method would require a split accuracy range where two ranges would be required - the requirement of $\pm 0.01^{\circ}$ would remain for low pitch attitudes and a yet-to-be defined accuracy would need to be established for model attitudes outside of this range. For purposes of this test, the range delimiter was set to near $5^{\circ}$. 
This method would use two channels set to two different ranges. One channel would be the high accuracy channel set to a voltage range with resolution capable of maintaining the required $0.01^{\circ}$ accuracy. Input above or below the range of this channel could saturate the data system and potentially cause problems for the subsequent readings while the system recovers. Circuitry diagramed in Appendix I is designed to avoid this mishap by having amplifiers that saturate or clip the signal. This signal can then be scaled with a voltage divider to only allowing signal levels within the range of the data system channel. The second channel would be set to a higher voltage range having less resolution but allowing for larger model attitude settings.

During this test the data system ranges were set to $640 \mathrm{mV}$ for the high resolution channel and $2.5 \mathrm{~V}$ for the low resolution channel. This provided a high accuracy saturation range of about $\pm 7^{\circ}$ and a usable range of $\pm 5^{\circ}$. This extra 2 degrees of range provides some room in the event of model attitude changes (due to dynamics) creating signals at or near the $7^{\circ}$ saturation limit. The high range allowed a model attitude of $56^{\circ}$ before saturation and a usable range of $50^{\circ}$. Fifty degrees was well beyond the parameters of this test. Software to flag the correct channel to read would need to be written for robust operation.

\section{Results}

\section{A. AoA Filter Testing}

Filter testing was conducted as described above and was intended to find the optimum maximum between filter lag and data quality. In other words, the filtering was reduced in order to lessen the lag but the price one pays for this is data quality. As the filtering decreased the lag decreased and the scatter in the data increased.

The data analysis was performed using the raw data (10 points averaged to make 1 research data point for this test). A standard deviation $(\sigma)$ was calculated for each set of 10 points. These standard deviations were then averaged for each cut-off frequency setting. As expected, the noise level increased drastically as the filter cut-off frequency was increased with $0.4 \mathrm{~Hz}$ having a $\sigma$ of 0.0016 and uses about $2.6 \%$ of the $0.01^{\circ}$ error-budget, for $1.2 \mathrm{~Hz} \sigma=0.0059$ and uses about $34 \%$ and for $4 \mathrm{~Hz} \sigma=0.022$ and uses about $470 \%$. Ten percent of the error budget would be the maximum allowable for this error source. Considering this, a change in the cutoff frequency up to about $0.65 \mathrm{~Hz}$ would be the maximum.

There were no timesavings due to filter cut-off frequency changes. In fact, the average times for each lighter filter went up. This is due to dynamics being filtered less and the control system taking longer to settle out in the presence of this extra noise. The input to the system was so noisy at the $4 \mathrm{~Hz}$ cut-off frequency that manual overrides had to be employed to take the data.

Both the noise levels and the measured and predicted times are plotted in Figure 5
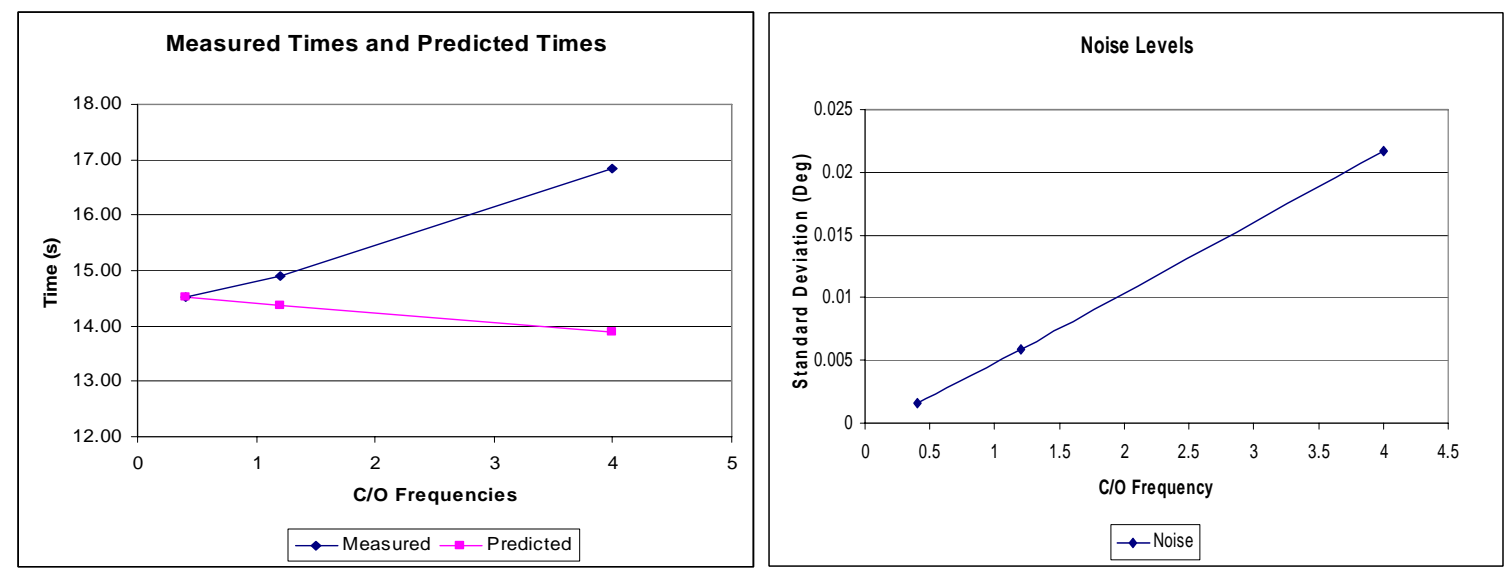

Figure 5: Filter timing and noise 


\section{B. Two-Channel Analog AoA}

The two-channel analog method was connected in January 2005 for test 153 and still remains connected. This has produced AoA data over several tests but the AoA readings were not rigorously being monitored. Data from tests 147 and 156 are shown here as representative samples of tests with relatively low (test 156) and high (test 147) dynamics. The high accuracy channel is of most concern and the data shown deals with that aspect of this method. There are some anomalies in the data that will be explained in the discussion of that particular data.

The analysis compared three AoA readings: pitch - the typical AoA measurement as read through the DVM, pitcha - an analog reading that did not pass through the clipping circuit and pitchn - the analog measurement read after passing through the clipping circuit. These comparisons were made at Mach numbers: $0.8,0.5$, and 0.0. Figure 6 shows differences between the three readings (pitch - pitcha, pitchpitchn and pitcha-pitchn) for test 147 and Figure 7 shows the same for test 156.
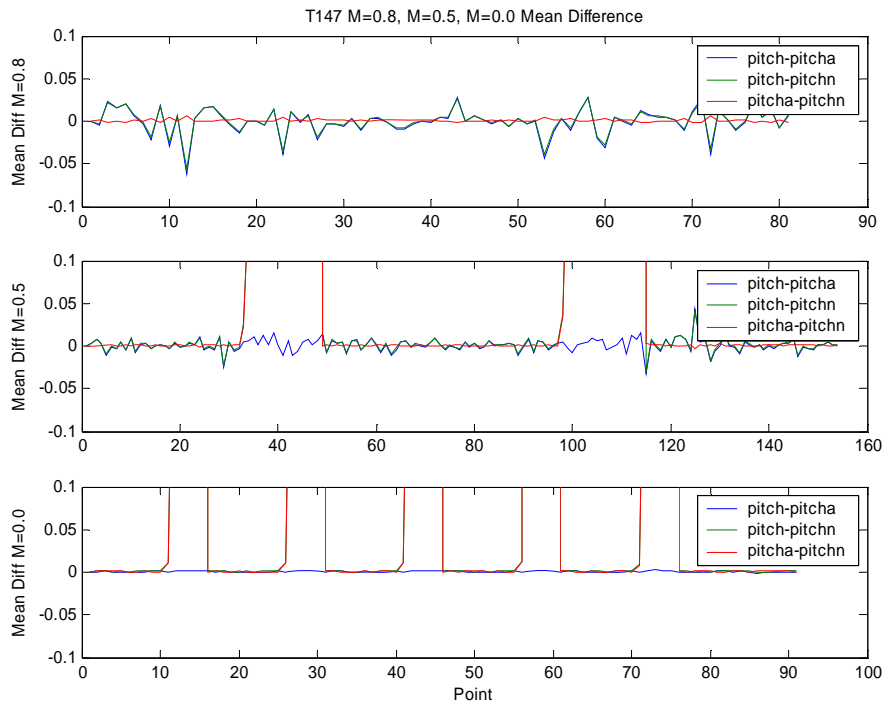

Figure 6: Differences between the AoA measurement methods for NTF Test 147
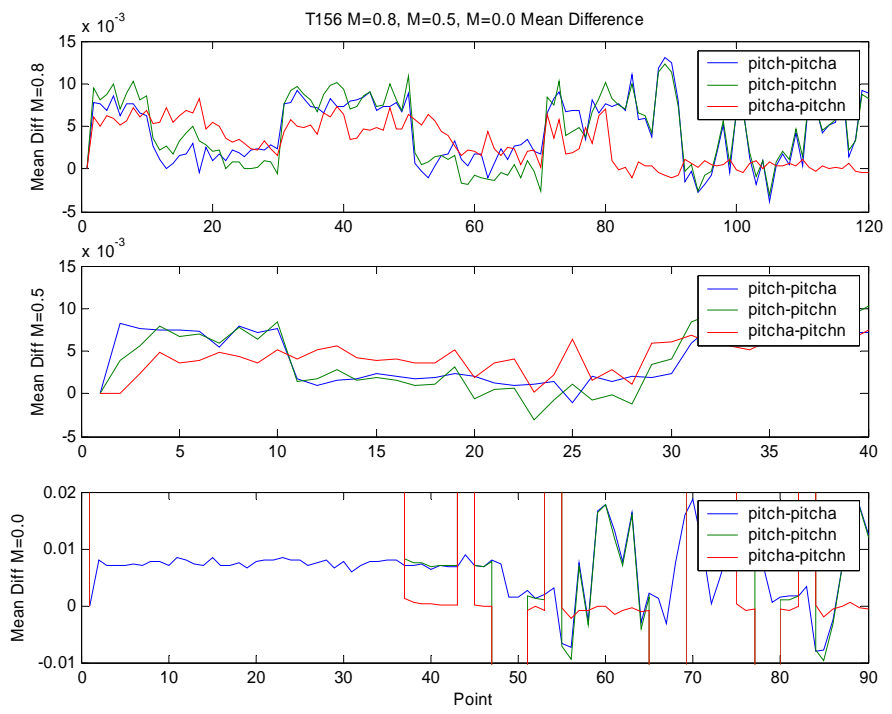

Figure7: Differences between the AoA measurement methods for NTF Test 156 
In Figure 6 plots $\mathrm{M}=0.0$ and $\mathrm{M}=0.5$ and Figure 7 plot $\mathrm{M}=0.0$ notice that there are several places were the plot goes beyond the $\mathrm{Y}$-axis range. These are places where the pitch angle went above or below the saturation range of the clipping circuit (pitchn reading). Beyond the saturation point pitchn remains constant causing large excursions in the differences between pitch and pitcha. There was also a large bias $\left(0.08^{\circ}\right)$ on several occasions in test 156 . Patterns in this biased data matched well with patterns in the nonbiased data so, for purposes of this analysis, the bias was assumed to be from some source that could be controlled or eliminated and was subtracted out. Mach $=0.0$ on test 156 was the exception in that the bias was not subtracted out due to the volume of points either shifted by bias or out of range of the clipping circuit. The last thing to notice in the data is the dependence on roll. Looking at Figure 7 in the $M=0.8$ plot notice that there is a pattern where the difference regularly vacillates between about $0.1^{\circ}$ and $0^{\circ}$ every 20 points. This data indicates the difference to be nearly $0.1^{\circ}$ when the model is in the upright position and the difference is nearly $0^{\circ}$ when the model in the inverted position. Why this occurred remains a mystery.

After removal of the biases, the standard deviation of the differences was calculated and these results are shown in Table 2. To understand what this table shows, take for example the $\sigma$ value of $0.004^{\circ}$ from T156 $\mathrm{M}=0.8$ for the differences between pitch and pitchn. This shows that $68 \%$ of the differences lie within $0.004^{\circ}$ of each other. What would be acceptable is to have $95 \%$ of the differences lying within $0.002^{\circ}$.

\begin{tabular}{|c|c|c|c|}
\hline & Pitch-Pitcha & itch-Pitch & rcha- \\
\hline $\mathrm{T} 156 \mathrm{M}=0.8$ & 0.0037 & 0.0040 & 0.0025 \\
\hline $\mathrm{T} 156 \mathrm{M}=0.5$ & 0.0030 & 0.0039 & 0.0019 \\
\hline $\mathrm{T} 156 \mathrm{M}=0$ & 0.0052 & 0.1888 & 0.1885 \\
\hline $\mathrm{T} 147 \mathrm{M}=0.8$ & 0.0158 & 0.0143 & 0.0016 \\
\hline $\mathrm{T} 147 \mathrm{M}=0.5$ & 0.0078 & 0.0067 & 0.0008 \\
\hline $147 \mathrm{M}=0$ & 0.0008 & 0.0021 & 0.0020 \\
\hline
\end{tabular}

Table 2: Standard deviation values for the AoA differences

\section{Conclusions}

The growing need to become more efficient has driven the NTF to explore ways to achieve more economical operation. The data suggests that a change of the cut-off frequency in the AoA filter from $0.4 \mathrm{~Hz}$ to $0.65 \mathrm{~Hz}$ would be acceptable from a percent of error-budget stand but there is no resulting savings in time to make the effort worthwhile.

There were unexplainable irregularities present in the data available for comparing the two-channel analog method to the DVM method of measuring AoA. These irregularities may have been explainable if more rigorous observations were made during the test. Some effort was attempted to compensate for these irregularities but this certainly adds some degree of uncertainty to the analysis. From the results shown above this method does not appear to satisfy the requirements for the NTF but given the irregularities in these tests, another data set that has been monitored more meticulously should be considered before abandoning it.

The real problem brought to light in test 153 was the control system itself. The long signal path from the on-board AoA to the drive control system creates many opportunities to reduce the time between data points. Some options for improvement are:

1) Make a direct path from the AoA signal conditioner directly to the Micro $C$ thus eliminating the DVM, NEFF data acquisition unit, and the RCS.

2) Make the attitude control system more of an open loop architecture system instead of closed loop one. This could be done using timed incremental moves based sting deflection estimates, current model position and desired step size. 
3) Open the tolerance on the set-point target. It is tremendously difficult for dynamic conditions to converge on a particular set point and requires an incredible amount of resources to accomplish it. As long as the measured values at the point where data was taken are accurate, researchers can compare the data point to the curve instead of doing a point to point comparison.

Several wind tunnel facilities around the country take substantially less time in positioning their models. A new study taking a systems engineering approach to the entire model attitude positioning system, instead of just the AoA components, is necessary to substantially reduce time between data points. With this type of an approach the NTF could match other facility model setting times.

\section{Acknowledgements}

I would like to acknowledge Richard DeLoach, Dr. Peter Parker and Dr. Michael Hemsch for their contributions during the data analysis and the staff at the NTF for allotting tunnel time and resources to mine the data.

\section{References}

\footnotetext{
${ }^{1}$ Putnam, Lawrence E., "Wind Tunnel Productivity Status and Improvement Activities at NASA Langley Research Center" AIAA Paper No.96-2260, 19th AIAA Advanced Measurement and Ground Testing Technology Conference, New Orleans, LA, June 17-20, 1996

${ }^{2}$ Kegelman, Jerome T., "Accelerating Ground-Test Cycle Time; the Six-Minute Model Change and Other Visions for the 21st Century" AIAA Paper No. 98-0142, 36th Aerospace Sciences Meeting and Exhibit, Reno, NV, Jan. 12-15, 1998.

${ }^{3}$ Crawford, Bradley L., Finley, Tom D., "Results from a Sting Whip Correction Verification Test at the Langley 16Foot Transonic Tunnel”, AIAA 2002-0879, 40th Aerospace Sciences Meeting and Exhibit, Reno, NV, Jan. 2002

${ }^{4}$ Steinle, F., and Stanewsky, E., "Wind Tunnel Flow Quality and Data Accuracy Requirements”, AGARD-AR-184, November 1982.

${ }^{5}$ Foster, Jean M., Adcock, Jerry B., "Users Guide for the National Transonic Facility Research Data System”, NASA TM-110242, April 1996
} 


\section{Appendix I}

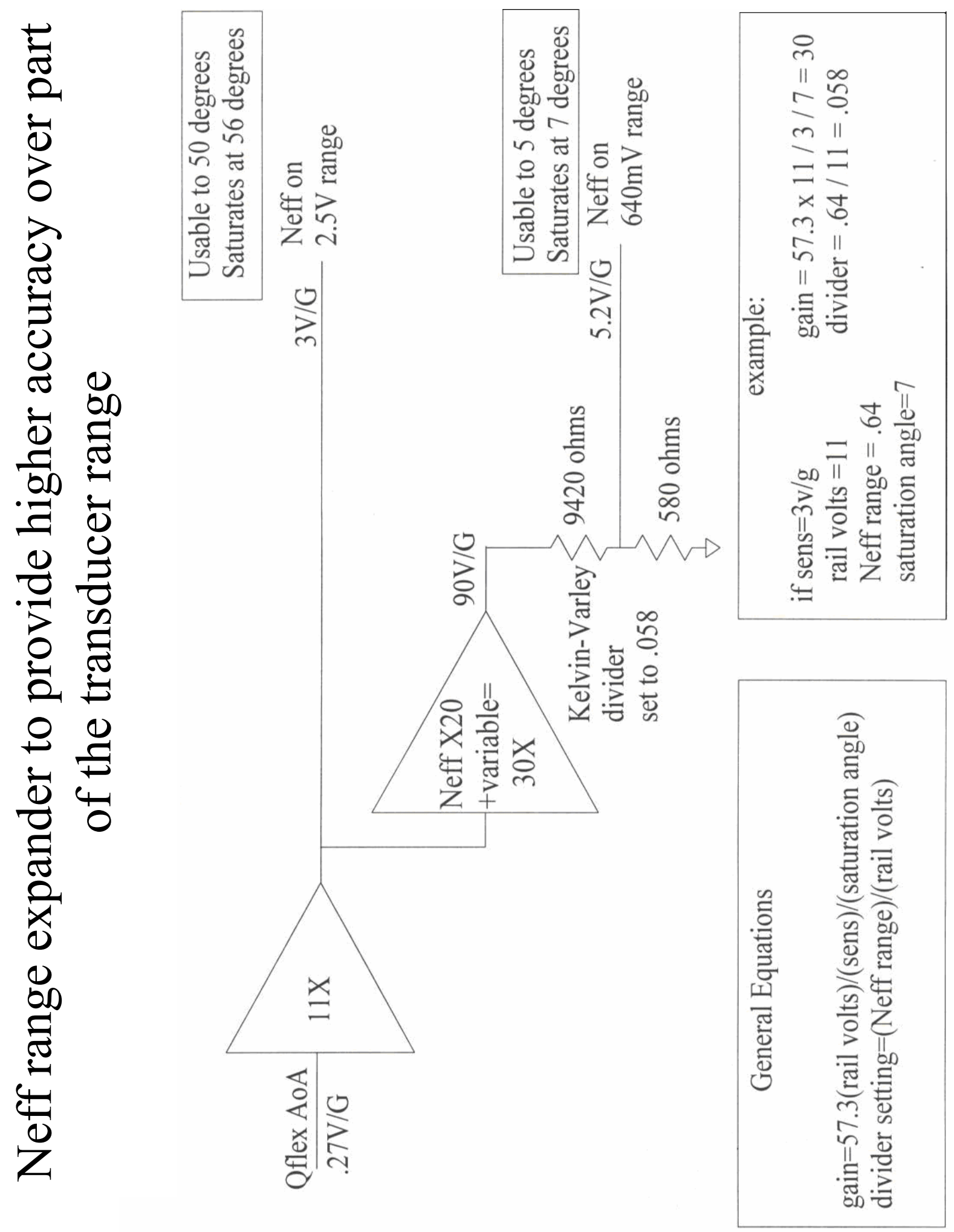

